\title{
Genetic polymorphism of merozoite surface proteins 1 and 2 of Plasmodium falciparum in the China-Myanmar border region
}

\author{
Cang-Lin Zhang ${ }^{1 \dagger}$, Hong-Ning Zhou ${ }^{1 \dagger}$, Quan Liu ${ }^{2,3^{*}}$ (I) and Ya-Ming Yang ${ }^{1 *}$
}

\begin{abstract}
Background: Malaria is a major public health problem in the China-Myanmar border region. The genetic structure of malaria parasite may affect its transmission model and control strategies. The present study was to analyse genetic diversity of Plasmodium falciparum by merozoite surface proteins 1 and 2 (MSP1 and MSP2) and to determine the multiplicity of infection in clinical isolates in the China-Myanmar border region.
\end{abstract}

Methods: Venous blood samples (172) and filter paper blood spots (70) of P. falciparum isolates were collected from the patients of the China-Myanmar border region from 2006 to 2011. The genomic DNA was extracted, and the msp1 and msp2 genes were genotyped by nested PCR using allele-specific primers for $P$. falciparum.

Results: A total of 215 P. falciparum clinical isolates were genotyped at the msp1 (201) and msp2 (204), respectively. For the msp1 gene, MAD20 family was dominant (53.49\%), followed by the K1 family (44.65\%), and the RO33 family (12.56\%). For the msp2 gene, the most frequent allele was the FC27 family (80.93\%), followed by the 3D7 family (75.81\%). The total multiplicity of infection (MOI) of msp1 and msp2 was 1.76 and 2.21, with a prevalence of $64.19 \%$ and $72.09 \%$, respectively. A significant positive correlation between the $\mathrm{MOI}$ and parasite density was found in the msp1 gene of P. falciparum. Sequence analysis revealed 38 different alleles of msp1 (14 K1, 23 MAD20, and 1 RO33) and 52 different alleles of msp2 (37 3D7 and 15 FC27).

Conclusion: The present study showed the genetic polymorphisms with diverse allele types of $m s p 1$ and $m s p 2$ as well as the high $\mathrm{MOI}$ of $P$. falciparum clinical isolates in the China-Myanmar border region.

Keywords: Plasmodium falciparum, Merozoite surface protein, Genetic polymorphism, The China-Myanmar border region

\section{Background}

Malaria is still one of the most important life-threatening parasitic diseases in tropical and subtropical areas. There were approximate 219 million malaria cases and 435,000 deaths in the world in 2017 [1]. In Southeast Asia, the Greater Mekong Subregion (GMS) is one of the high

\footnotetext{
*Correspondence: liuquan1973@hotmail.com; yangymsm@126.com

${ }^{\dagger}$ Cang-Lin Zhang and Hong-Ning Zhou contributed equally to this work

${ }^{1}$ Yunnan Provincial Key Laboratory of Vector-borne Diseases Control and Research, Yunnan Provincial Center of Malaria Research, Yunnan Institute of Parasitic Diseases, Pu'er 665000, Yunnan, China

${ }^{2}$ School of Life Sciences and Engineering, Foshan University,

Foshan 528225, Guangdong, China

Full list of author information is available at the end of the article
}

malarious areas, with the co-existence of different species and emergence of drug-resistant parasites. In Yunnan Province, the most high malarious endemic region in China, annual incidence has decreased from 196/100,000 in 2006 to $0.7 / 100,000$ in 2016, where indigenous malaria transmission is mostly concentrated in Yingjiang County that is adjacent to the Kachin State of Myanmar [2]. In addition, the malaria cases are also clustered on small spatial scales along the China-Myanmar border, which may be related to climatic, environmental, and ecological factors favoring vector survival [3, 4], as well as to the high malaria endemicity in the adjacent Kachin State of Myanmar.

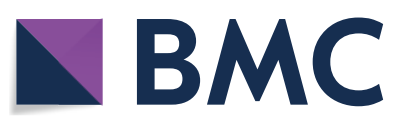

C The Author(s) 2019. This article is distributed under the terms of the Creative Commons Attribution 4.0 International License (http://creativecommons.org/licenses/by/4.0/), which permits unrestricted use, distribution, and reproduction in any medium, provided you give appropriate credit to the original author(s) and the source, provide a link to the Creative Commons license, and indicate if changes were made. The Creative Commons Public Domain Dedication waiver (http://creativecommons.org/ publicdomain/zero/1.0/) applies to the data made available in this article, unless otherwise stated. 
Genetic diversity of the parasites provides useful information on the parasite populations and control efforts against malaria. Polymorphic genetic markers of $P$. falciparum include the merozoite surface protein 1 (MSP1) and MSP2 that have been used to evaluate the genetic diversity of malaria parasites [5-10]. Based on the sequence analysis of $P$. falciparum isolates from different endemic areas, the $m s p 1$ gene is divided into two allelic types of MAD20 and K1, whereas the highly polymorphic block 2 is represented by three allelic types of $\mathrm{K} 1, \mathrm{RO} 33$ and MAD20 [11]. In contrast, the $m s p 2$ gene is grouped into two different allelic types of 3D7 and FC27 [12-14]. These two polymorphic markers have been used to study the $P$. falciparum population in northeastern Myanmar, suggesting a highly diverse parasite population [15]. Due to the dramatic changes of the malaria situation in Yunnan Province, China, in recent years, this study aimed to investigate the genetic diversity of the $P$. falciparum populations along the China-Myanmar border region using two polymorphic markers MSP1 and MSP2.

\section{Methods \\ Collection of clinical parasite samples}

This study was approved by the Ethical Review Board of Yunnan Institute of Parasitic Diseases, China. A total of 242 P. falciparum clinical samples were collected from malaria patients attending local hospitals along the China-Myanmar border during 2006-2011. These patients came from Laza, Nawei, Mangdong, and Nankajiang in Myanmar, and Tengchong, Yingjiang and Mengla in Yunnan Province, China (Fig. 1). All patients were diagnosed with $P$. falciparum infection by Giemsastained blood smears and microscope examination at the local hospitals, and further confirmed by a nested PCR [16]. Two hundred and fifty microlitres of finger-pricked blood was spotted on the $3 \mathrm{~mm}$ Whatman filter paper

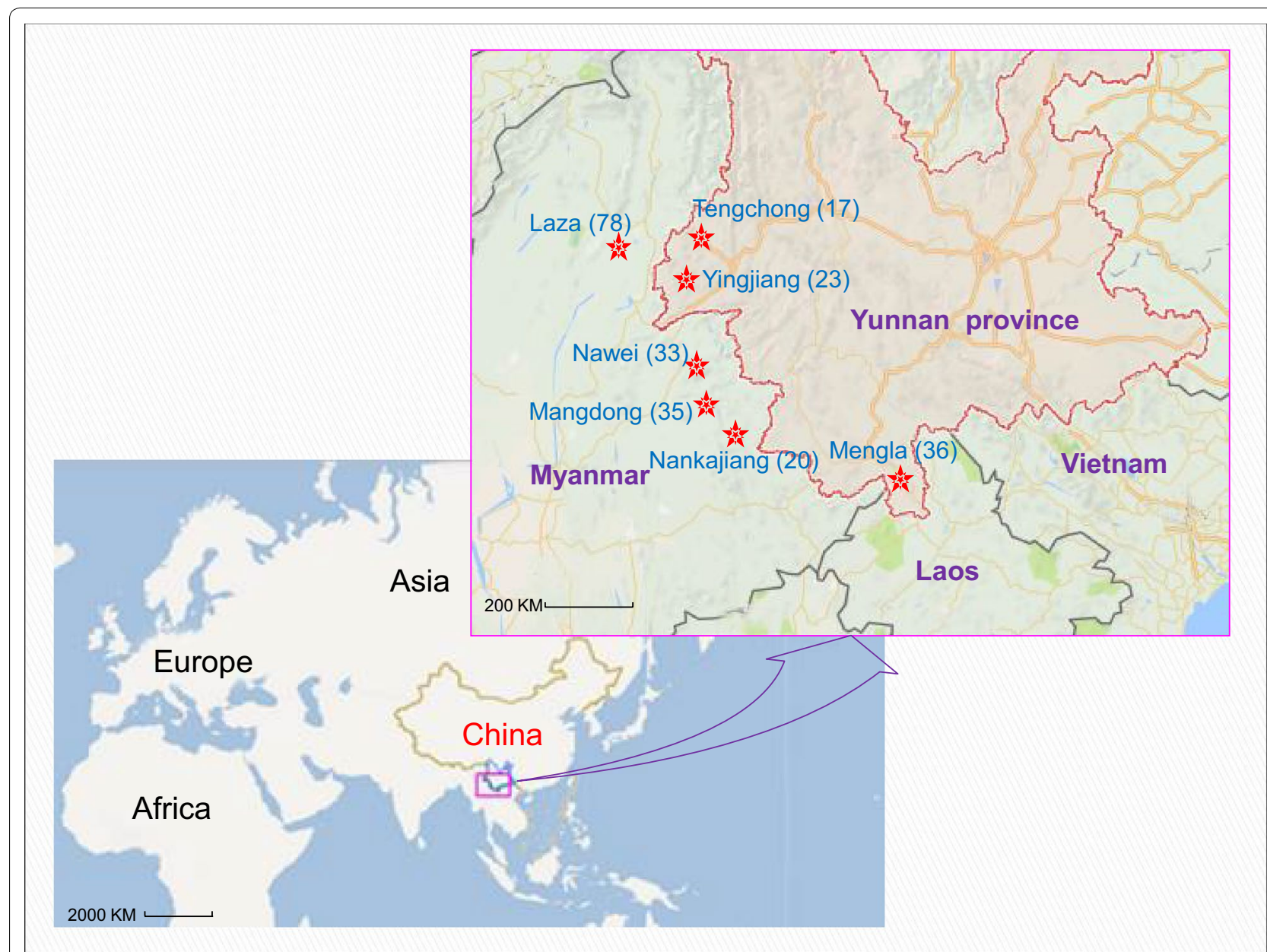

Fig. 1 Map of the China-Myanmar border region showing the sampling sites that indicated with red star. The map was prepared by using the website of https://map.baidu.com/ 
(GE Healthcare, USA), dried, and stored at $4{ }^{\circ} \mathrm{C}$ until further analysis.

\section{PCR amplification}

Genomic DNA of parasite was extracted from the filter paper by using the QIAamp ${ }^{\circledR}$ DNA Mini Kit (Qiagen, Germany). The $m s p 1$ and $m s p 2$ genes were genotyped by a nested PCR using allele-specific primers as described elsewhere [17]. The PCR products were analysed on $2 \%$ agarose gel electrophoresis and stained with GoldView (Shanghai, China), whose size was determined using the standard DNA ladder marker (Toyobo, Japan).

The PCR products were sequenced and deposited in the GenBank with accession numbers MG004320MG004381 for the K1 type, MG004447-MG004517 for the MAD20 type, and MG004518-MG004527 for the RO33 type of msp1; MG004219-MG004319 for the 3D7 type and MG004382-MG004446 for the FC27 type of msp2.

\section{Multiplicity of infection}

Multiplicity of infection (MOI) was defined as the largest number of alleles at each locus, and single infection was that with only one allele per locus at all of the genotyped loci $[15,18]$.

\section{Statistical analysis}

All statistical analyses were conducted with the software Statistical Package for Social Sciences (SPSS) version 23.0. The frequencies of the different combinations of alleles in seven studied areas were assessed by KruskalWallis test, and normally distributed continuous data were evaluated by analysis of variance (ANOVA). The Spearman's rank correlation coefficient test was calculated to assess relationships between MOI and parasite densities or ages in these patients, respectively. The difference was considered statistically significant when $P$ value was less than 0.05 .

\section{Results}

\section{General characteristics of included patients}

A total of 242 malaria patients were enrolled into this study during 2006-2011. Among these patients, there were 200 patients who were confirmed by a nested PCR to be infected with $P$. falciparum, 14 patients infected with Plasmodium vivax, and 15 patients co-infected with $P$. falciparum and $P$. vivax, and 13 patients excluded from the study as the genomic DNA from these patients were not successfully extracted (Fig. 2). All the P. falciparum clinical isolates (215 patients) were included in this study. Of these, 65 patients were from Yunnan province, China, and 150 from Myanmar. Sixty-eight patients

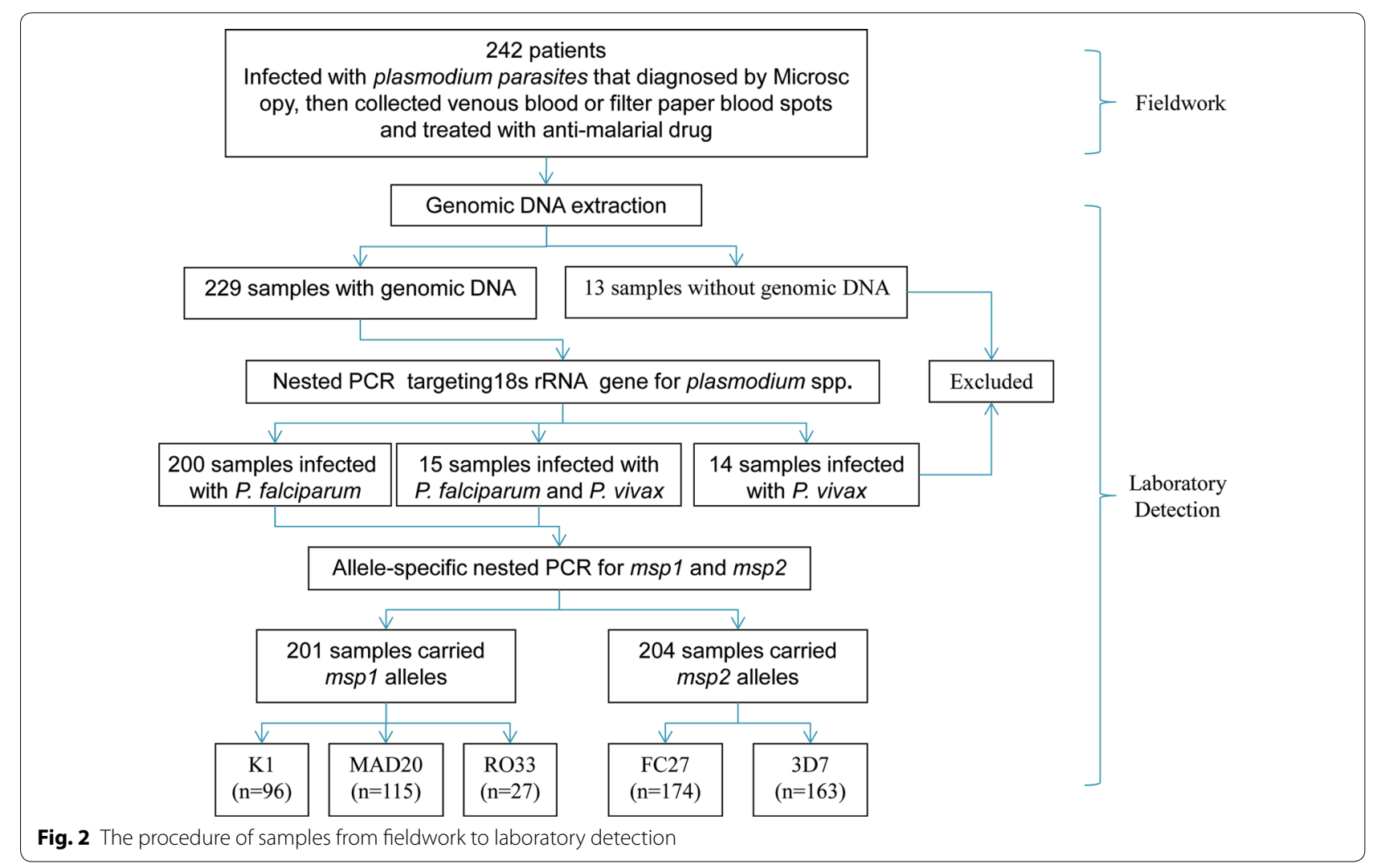


were children under 19 years, 11 patients were more than 49 years old, and other 136 patients were between 19 and 49 years old.

\section{Allelic polymorphism of $m s p 1$ and $m s p 2$}

Among 215 P. falciparum clinical isolates, 201 (93.49\%) and $204(94.88 \%)$ samples were genotyped at the $m s p 1$ and $m s p 2$, respectively. For $m s p 1$ gene, the MAD20 family was dominant $(53.49 \%)$ and included 7 different band sizes (120-280 bp), followed by the K1 family (44.65\%) that included 9 different band sizes (150-320 bp), and the RO33 family (12.56\%) that contained 3 different band sizes (150-200 bp) (Table 1, Fig. 3). The alleles with a high frequency for MAD20, K1 and RO33 were $180 \mathrm{bp}$ (30.38\%), $180 \mathrm{bp}(30 \%)$ and $150 \mathrm{bp}(64.10 \%)$, respectively.

For $m s p 2$ gene, the FC27 family (80.93\%) showed the higher number of alleles, with 8 different band sizes (250-700 bp) (Table 1, Fig. 3), followed by the 3D7 family $(75.81 \%)$ that included 9 different band sizes (400$760 \mathrm{bp})$. The most frequent alleles of FC27 and 3D7 were 700 bp (19.56\%) and 550 bp (28.22\%), respectively.

The total rate of MOI for $m s p 1$ and $m s p 2$ was $64.19 \%$ and $72.09 \%$, respectively. The alleles of $P$. falciparum clinical isolates were K1 (30.23\%), MAD20 (39.07\%), RO33 (8.84\%), K1+MAD20 (11.63\%), KI+RO33
(0.93\%), MAD20 + RO33 (0.93\%), K1 + MAD20 + RO33 (1.86\%) for $m s p 1$ and FC27 (19.07\%), 3D7 (13.95\%), FC27 + 3D7 (61.86\%) for $m s p 2$, respectively, while none of above-mentioned combination alleles of msp1 (such as $\mathrm{K} 1+\mathrm{MAD} 20, \mathrm{KI}+\mathrm{RO} 33, \mathrm{MAD} 20+\mathrm{RO} 33$, and $\mathrm{K} 1+\mathrm{MAD} 20+\mathrm{RO} 33)$ were be found in the isolates from Tengchong of Yunnan and Nankajiang of Myanmar (Table 1 and Fig. 4). There were a statistical difference in prevalences of the K1, MAD20, and RO33 families and their different MOI of $m s p 1\left(X^{2}=14.478 ; P=0.025\right)$ or FC27, 3D7, and FC27/3D7 alleles of $m s p 2\left(X^{2}=30.617\right.$; $P=0.000)$ between the seven studied areas.

\section{The MOI distribution of allelic families across different parasite density and age groups}

Almost all patients were detected to have multiclonal infections, with a mean MOI of $1.76 \pm 0.85$ for $m s p 1$ and $2.21 \pm 1.29$ for $m s p 2$. The MOI values of $m s p 1$ and $m s p 2$ for each parasite density and age groups are summarized in Tables 2 and 3. There was a significant positive correlation between the MOI and parasite density for $m s p 1$ (Spearman's rank coefficient $=0.208$; $P=0.002$ ) (Additional file 1: Table S1), but no positive correlation for msp2 (Spearman's rank coefficient $=-0.040 ; P=0.564$ ) was found. Additionally, no

Table 1 Prevalence of $m s p 1$ and msp2 allelic types in the China-Myanmar border region

\begin{tabular}{|c|c|c|c|c|c|c|c|c|}
\hline Allelic types & $\begin{array}{l}\text { Mengla, } \\
\text { Yunnan } \\
n(\%) \\
n=28\end{array}$ & $\begin{array}{l}\text { Tengchong, } \\
\text { Yunnan } \\
\mathrm{n}(\%) \\
\mathrm{n}=16\end{array}$ & $\begin{array}{l}\text { Yingjiang, } \\
\text { Yunnan } \\
\text { n (\%) } \\
n=21\end{array}$ & $\begin{array}{l}\text { Laza, } \\
\text { Myanmar } \\
\text { n (\%) } \\
\text { n=77 }\end{array}$ & $\begin{array}{l}\text { Nawei, } \\
\text { Myanmar } \\
\text { n (\%) } \\
n=26\end{array}$ & $\begin{array}{l}\text { Nankajiang, } \\
\text { Myanmar } \\
\mathrm{n}(\%) \\
\mathrm{n}=19\end{array}$ & $\begin{array}{l}\text { Mangdong, } \\
\text { Myanmar } \\
\mathrm{n}(\%) \\
\mathrm{n}=28\end{array}$ & $\begin{array}{l}\text { Total } \\
n(\%) \\
n=215\end{array}$ \\
\hline \multicolumn{9}{|l|}{ mspl } \\
\hline $\mathrm{K} 1$ & $10(35.71)$ & $5(31.25)$ & $5(23.81)$ & $16(20.78)$ & $9(34.62)$ & $7(36.84)$ & $13(46.43)$ & $65(30.23)$ \\
\hline MAD20 & $11(39.29)$ & $9(56.25)$ & $10(47.62)$ & $28(36.36)$ & $8(30.77)$ & $7(36.84)$ & $11(39.29)$ & $84(39.07)$ \\
\hline $\mathrm{RO} 33$ & 0 & $1(6.25)$ & 0 & 15 (19.48) & $1(3.85)$ & $1(5.26)$ & $1(3.57)$ & $19(8.84)$ \\
\hline K1/MAD20 & $7(25.00)$ & 0 & $2(9.52)$ & $8(10.39)$ & $6(23.08)$ & 0 & $2(7.14)$ & $25(11.63)$ \\
\hline KI/RO33 & 0 & 0 & 0 & $2(2.6)$ & 0 & 0 & 0 & $2(0.93)$ \\
\hline MAD20/RO33 & 0 & 0 & 0 & $2(2.6)$ & 0 & 0 & 0 & $2(0.93)$ \\
\hline $\begin{array}{l}\text { K1/MAD20/ } \\
\text { RO33 }\end{array}$ & 0 & 0 & $3(14.29)$ & $1(1.3)$ & 0 & 0 & 0 & $4(1.86)$ \\
\hline Negative & 0 & $1(6.25)$ & $1(4.76)$ & $5(6.49)$ & $2(7.69)$ & $4(21.05)$ & $1(3.57)$ & $14(6.51)$ \\
\hline $\begin{array}{c}\text { Multiclonal } \\
\text { isolates }\end{array}$ & $22(78.57)$ & $12(75.00)$ & $13(61.90)$ & $51(66.23)$ & $12(46.15)$ & $3(15.80)$ & 25 (89.29) & $138(64.19)$ \\
\hline Mean MOI & $1.83 \pm 0.59$ & $1.94 \pm 0.68$ & $2.01 \pm 1.28$ & $1.82 \pm 0.94$ & $1.44 \pm 0.58$ & $1.15 \pm 0.40$ & $1.98 \pm 0.51$ & $1.76 \pm 0.85$ \\
\hline \multicolumn{9}{|l|}{ msp2 } \\
\hline FC27 & $1(3.57)$ & $2(12.5)$ & $11(52.38)$ & $21(27.27)$ & $1(3.85)$ & $2(10.53)$ & $3(10.71)$ & 41 (19.07) \\
\hline 3D7 & $3(10.71)$ & 0 & 0 & $8(10.39)$ & $6(23.08)$ & $12(63.16)$ & $1(3.57)$ & 30 (13.95) \\
\hline FC27/3D7 & $23(82.14)$ & $13(81.25)$ & $9(42.86)$ & $43(55.84)$ & 19 (73.08) & $3(15.79)$ & $23(82.14)$ & 133 (61.86) \\
\hline Negative & $1(3.57)$ & $1(6.25)$ & $1(4.76)$ & $5(6.49)$ & 0 & $2(10.53)$ & $1(3.57)$ & $11(5.12)$ \\
\hline $\begin{array}{c}\text { Multiclonal } \\
\text { isolates }\end{array}$ & $26(92.86)$ & $14(87.50)$ & $19(90.48)$ & $52(67.53)$ & $21(80.77)$ & $3(15.79)$ & $20(71.43)$ & 155 (72.09) \\
\hline Mean MOI & $3.27 \pm 0.99$ & $3.29 \pm 1.20$ & $2.57 \pm 1.21$ & $1.86 \pm 1.03$ & $2.63 \pm 1.51$ & $1.13 \pm 0.38$ & $2.21 \pm 1.08$ & $2.21 \pm 1.29$ \\
\hline
\end{tabular}



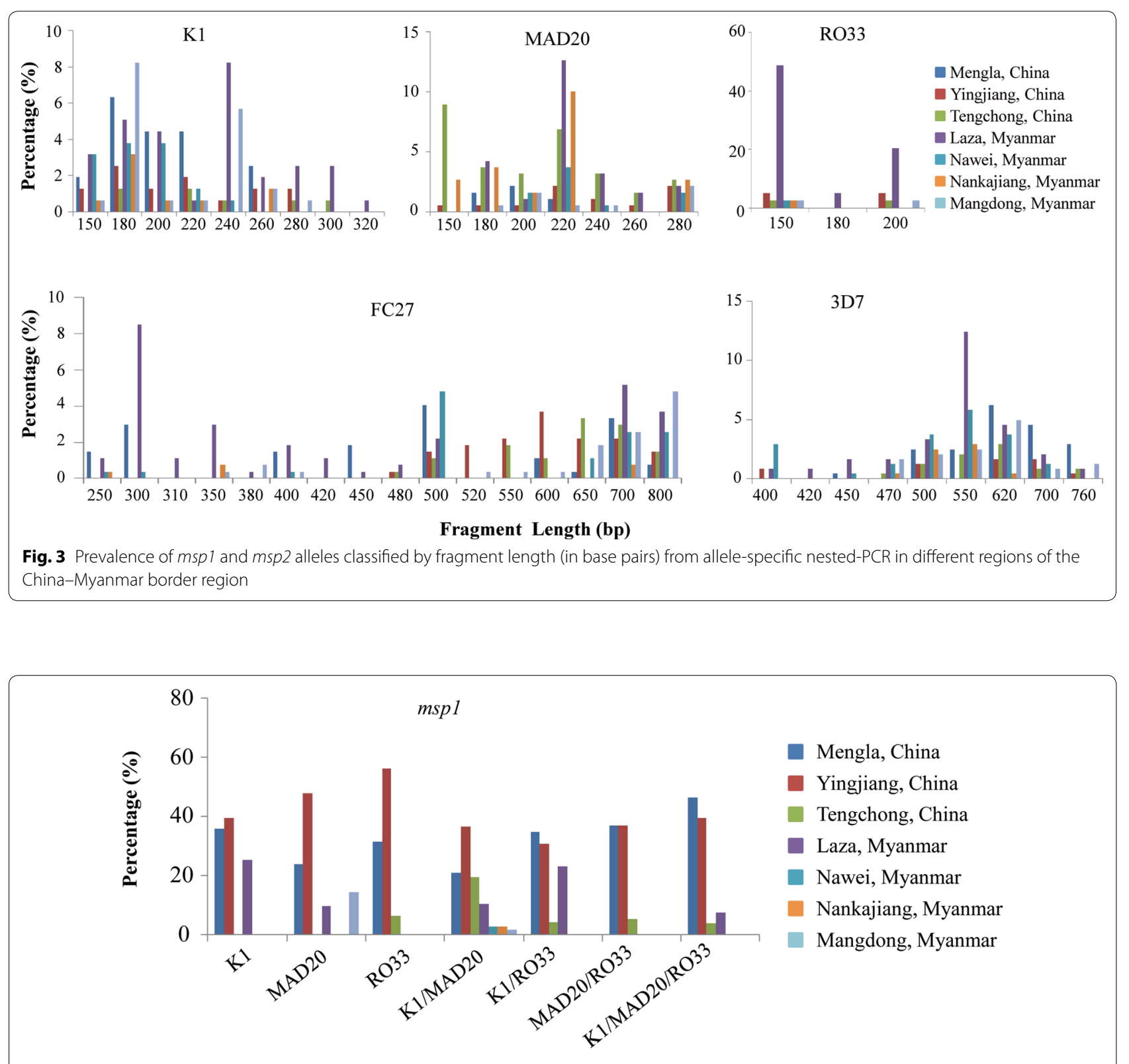

Mengla, China

- Yingjiang, China

- Tengchong, China

Laza, Myanmar

Nawei, Myanmar

Nankajiang, Myanmar

Mangdong, Myanmar

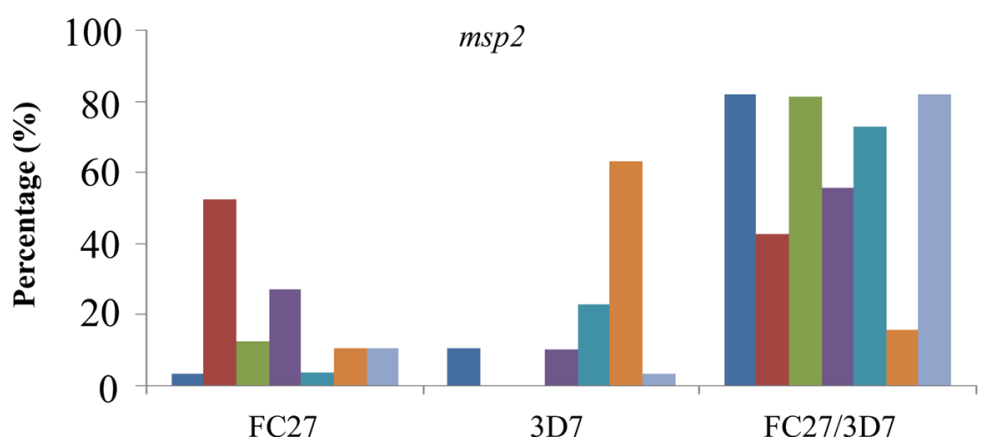

Fig. 4 Multiplicity of infection of $m s p 1$ and msp2 alleles in different regions of the China-Myanmar border region 
Table 2 Distribution of $m s p 1$ and $m s p 2$ allelic types of $P$. falciparum among different age groups in the China-Myanmar border region

\begin{tabular}{|c|c|c|c|c|c|c|c|}
\hline \multirow[t]{4}{*}{ Allelic types } & \multicolumn{6}{|c|}{ Age group (years) } & \multirow{3}{*}{$\begin{array}{l}\text { Total } \\
\text { n (\%) }\end{array}$} \\
\hline & $<9$ & 9-19 & $19-29$ & $29-39$ & $39-49$ & $\geq 49$ & \\
\hline & n (\%) & n (\%) & n (\%) & n (\%) & n (\%) & n (\%) & \\
\hline & $n=11$ & $n=57$ & $n=70$ & $n=40$ & $n=26$ & $n=11$ & $n=215$ \\
\hline \multicolumn{8}{|l|}{ MSP-1 } \\
\hline K1 & $4(36.36)$ & $17(29.82)$ & $23(32.86)$ & $9(22.5)$ & $11(42.31)$ & $1(9.09)$ & $65(30.23)$ \\
\hline MAD20 & $2(18.18)$ & $21(36.84)$ & $33(47.14)$ & $13(32.5)$ & $10(38.46)$ & $5(45.45)$ & $84(39.07)$ \\
\hline $\mathrm{RO} 33$ & $0(0)$ & $7(12.28)$ & $2(2.86)$ & $6(15)$ & $1(3.85)$ & $3(27.27)$ & 19 (8.84) \\
\hline K1/MAD20 & $4(36.36)$ & $4(7.02)$ & $5(7.14)$ & $8(20)$ & $3(11.54)$ & $1(9.09)$ & $25(11.63)$ \\
\hline $\mathrm{KI} / \mathrm{RO} 33$ & $0(0)$ & $1(1.75)$ & $0(0)$ & $1(2.5)$ & $0(0)$ & $0(0)$ & $2(0.93)$ \\
\hline MAD20/RO33 & $0(0)$ & $1(1.75)$ & $0(0)$ & $1(2.5)$ & $0(0)$ & $0(0)$ & $2(0.93)$ \\
\hline K1/MAD20/RO33 & $0(0)$ & $1(1.75)$ & $2(2.86)$ & $0(0)$ & $1(3.85)$ & $0(0)$ & $4(1.86)$ \\
\hline Negative & $1(9.09)$ & $5(8.77)$ & $5(7.14)$ & $2(5)$ & $0(0)$ & $1(9.09)$ & $14(6.51)$ \\
\hline Multiclonal isolates & $4(36.36)$ & $7(12.28)$ & $7(10)$ & $10(25)$ & $4(15.38)$ & $1(9.09)$ & $33(15.35)$ \\
\hline Mean MOI & $1.87 \pm 0.77$ & $1.88 \pm 0.80$ & $1.80 \pm 0.90$ & $1.74 \pm 0.84$ & $1.44 \pm 0.57$ & $1.73 \pm 1.18$ & $1.76 \pm 0.85$ \\
\hline \multicolumn{8}{|l|}{ MSP-2 } \\
\hline FC27 & $1(9.09)$ & $12(21.05)$ & $10(14.29)$ & $13(32.5)$ & $2(7.69)$ & $3(27.27)$ & $41(19.07)$ \\
\hline 3D7 & $2(18.18)$ & $8(14.04)$ & $7(10)$ & $5(12.5)$ & $8(30.77)$ & $0(0)$ & $30(13.95)$ \\
\hline FC27/3D7 & $8(72.73)$ & $34(59.65)$ & $48(68.57)$ & $20(50)$ & $16(61.54)$ & $7(63.64)$ & $133(61.86)$ \\
\hline Negative & $0(0)$ & $3(5.26)$ & $5(7.14)$ & $2(5)$ & $0(0)$ & $1(9.09)$ & $11(5.12)$ \\
\hline Multiclonal isolates & $8(72.73)$ & $34(59.65)$ & $48(68.57)$ & $20(50)$ & $16(61.54)$ & $7(63.64)$ & $133(61.86)$ \\
\hline Mean MOI & $2.06 \pm 1.23$ & $2.09 \pm 1.14$ & $2.45 \pm 1.29$ & $2.16 \pm 1.24$ & $2.04 \pm 1.39$ & $2.28 \pm 1.72$ & $2.21 \pm 1.29$ \\
\hline
\end{tabular}

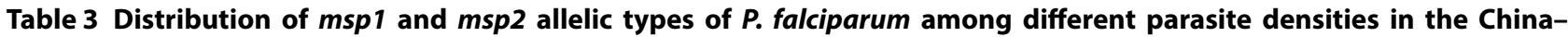
Myanmar border region

\begin{tabular}{|c|c|c|c|c|c|c|c|}
\hline \multirow[t]{4}{*}{ Allelic type } & \multicolumn{6}{|c|}{ Parasite density (no. of parasites $/ \mu$ l of blood) } & \multirow{3}{*}{$\begin{array}{l}\text { Total } \\
\text { n (\%) }\end{array}$} \\
\hline & $<500$ & $500-1000$ & $1000-2500$ & $2500-10,000$ & $10,000-100,000$ & $\geq 100,000$ & \\
\hline & n (\%) & n (\%) & n (\%) & n (\%) & n (\%) & n (\%) & \\
\hline & $n=11$ & $n=22$ & $n=44$ & $n=66$ & $n=61$ & $n=11$ & $n=215$ \\
\hline \multicolumn{8}{|l|}{ mspl } \\
\hline K1 & $4(36.36)$ & $9(40.91)$ & $18(40.91)$ & $18(27.27)$ & $14(22.95)$ & $2(18.18)$ & $65(30.23)$ \\
\hline MAD20 & $5(45.45)$ & $8(36.36)$ & $17(38.64)$ & $29(43.94)$ & $22(36.07)$ & $3(27.27)$ & $84(39.07)$ \\
\hline $\mathrm{RO} 33$ & $0(0)$ & $0(0)$ & $2(4.55)$ & $3(4.55)$ & $8(13.11)$ & $6(54.55)$ & 19 (8.84) \\
\hline K1/MAD20 & $2(18.18)$ & $5(22.73)$ & $2(4.55)$ & $9(13.64)$ & $7(11.48)$ & $0(0)$ & $25(11.63)$ \\
\hline $\mathrm{KI} / \mathrm{RO} 33$ & $0(0)$ & $0(0)$ & $0(0)$ & $0(0)$ & $2(3.28)$ & $0(0)$ & $2(0.93)$ \\
\hline MAD20/RO33 & $0(0)$ & $0(0)$ & $0(0)$ & $0(0)$ & $2(3.28)$ & $0(0)$ & $2(0.93)$ \\
\hline K1/MAD20/RO33 & $0(0)$ & $0(0)$ & $0(0)$ & $3(4.55)$ & $1(1.64)$ & $0(0)$ & $4(1.86)$ \\
\hline Negative & $0(0)$ & $0(0)$ & $5(11.36)$ & $4(6.06)$ & $5(8.2)$ & $0(0)$ & $14(6.51)$ \\
\hline Multiclonal isolates & $2(18.18)$ & $5(22.73)$ & $2(4.55)$ & $12(18.18)$ & $12(19.67)$ & $0(0)$ & $33(15.35)$ \\
\hline Mean MOI & $1.32 \pm 0.68$ & $1.52 \pm 0.73$ & $1.67 \pm 0.68$ & $1.91 \pm 0.86$ & $1.80 \pm 0.95$ & $2.02 \pm 0.83$ & $1.76 \pm 0.85$ \\
\hline \multicolumn{8}{|l|}{ msp2 } \\
\hline FC27 & $0(0)$ & $1(4.55)$ & $5(11.36)$ & $17(25.76)$ & $16(26.23)$ & $2(18.18)$ & $41(19.07)$ \\
\hline $3 \mathrm{D} 7$ & $1(9.09)$ & $5(22.73)$ & $10(22.73)$ & $6(9.09)$ & $3(4.92)$ & $5(45.45)$ & $30(13.95)$ \\
\hline FC27/3D7 & $10(90.91)$ & $15(68.18)$ & $26(59.09)$ & $41(62.12)$ & $38(62.3)$ & $3(27.27)$ & $133(61.86)$ \\
\hline Negative & $0(0)$ & $1(4.55)$ & $3(6.82)$ & $2(3.03)$ & $4(6.56)$ & $1(9.09)$ & $11(5.12)$ \\
\hline Multiclonal isolates & $10(90.91)$ & $15(68.18)$ & $26(59.09)$ & $41(62.12)$ & $38(62.3)$ & $3(27.27)$ & $133(61.86)$ \\
\hline Mean MOI & $1.32 \pm 0.68$ & $1.52 \pm 0.73$ & $1.67 \pm 0.68$ & $1.89 \pm 0.86$ & $1.80 \pm 0.95$ & $2.02 \pm 0.83$ & $2.21 \pm 1.29$ \\
\hline
\end{tabular}


significant correlation between age and MOI (Spearman's rank coefficient $=-0.12 ; P=0.08$ for $m s p 1$ and Spearman's rank coefficient $=0.007 ; P=0.917$ for $m s p 2$ ) was found. Furthermore, there was a significant difference of the MOI for the msp1 gene among the groups with different parasite densities $(\mathrm{F}=2.588 ; P=0.028)$, while no significant difference for $m s p 2(\mathrm{~F}=0.245$; $P=0.942)$ or for the MOI of $m s p 1 \quad(\mathrm{~F}=0.443 ; P=0.818)$ and $m s p 2(\mathrm{~F}=0.433 ; P=0.825)$ among groups with different ages were found.

\section{Sequence analysis of MSP1 and MSP2}

A total of 38 different alleles of $m s p 1$ were used for sequence analysis, including 14 for K1 family, 23 for MAD20, and 1 for RO33 (Additional file 2: Figure S1, Additional file 3: Figure S2). All K1-type alleles were found to have a 24-amino acid sequence: SPSSRSNTLPRSNTSSGASPPADA at the $5^{\prime}$-end and 10-amino acid sequence: NEEEITTKGA at the $3^{\prime}$-end. The central variable region always started with SAQ and terminated with SGT containing the difference number of tripeptide repetition, such as SAQ, SGP, and SGT. The diversity of MAD20 family was also caused by differences in repetitions of SGG, SVA and SVT, but the central variable region always started with SKG or SGG and ended with SVA. Only one amino acid sequence type of amino acids LKDGANTQVVAKPAGAVSTQSAKNPPGATVPSGTASTKGAIRSPGAANPSD was identified in the RO33 family. A total of 37 alleles of 3D7 and 15 alleles of FC27 in the $m s p 2$ gene were detected by sequence analysis of the block 3 region (Additional file 4: Figure S3, Additional file 5: Figure S4). The central variable region of 3D7 family included diverse amino acid repeat motifs that contained the different combinations of three amino acids: S, A, and G. The 3D7 family consisted of 12 different amino acids repeats and the 17 single amino acids.

The full sequences of 3D7 family were compared to the reference 3D7 (GenBank accession number X53832) (Additional file 4: Figure S3), showing deletion of 10 or 11 amino acids $\mathrm{PKG}(\mathrm{K} / \mathrm{N}) \mathrm{G}(\mathrm{E} / \mathrm{G} / \mathrm{K} / \mathrm{Q}) \mathrm{VQ}(\mathrm{E} / \mathrm{K} / \mathrm{P})(\mathrm{N} / \mathrm{P} / \mathrm{S})$ or $\operatorname{PKG}(\mathrm{K} / \mathrm{N}) \mathrm{G}(\mathrm{E} / \mathrm{G} / \mathrm{K} / \mathrm{Q}) \mathrm{VQ}(\mathrm{E} / \mathrm{K} / \mathrm{P})(\mathrm{N} / \mathrm{P} / \mathrm{S}) \mathrm{N}$ in the reference $3 \mathrm{D} 7$, which was common in field isolates from China-Myanmar border region. The dominant genotype of FC27 family was found to have one 32-amino acid ADTIASGSQSSTNSASTSTTNNGESQTTTPTA, followed by a conserved sequence ADTPTAT(E/K), and a two type of tandemly repeated units, SNSPSPPITTTE or SNSRSPPITTTE, repeated from two up to five times. All FC27 family had a 10-amino acid SSSSGNAPNK at the $5^{\prime}$-end and 3-amino acid $\mathrm{AP}(\mathrm{N} / \mathrm{K})$ or 6 -amino acid $\operatorname{APNAP}(K / N)$ at the $3^{\prime}$-end (Additional file 5: Figure S4).

\section{Discussion}

The genetic diversity of $P$. falciparum may affect the model of transmission and control strategies for the parasite. The pathogenicity, antigen specificity and antimalarial drug sensitivity of $P$. falciparum can be associated with their malarial genetic structure $[19,20]$. The genetic polymorphism analysis of $P$. falciparum field isolates is necessary and might shed light on the development of control strategies and effective vaccines against P. falciparum.

In the present study, a high genetic diversity of $m s p 1$ and $m s p 2$, including 19 different PCR products for $m s p 1$ (7 MAD20, $9 \mathrm{~K} 1$ and $3 \mathrm{RO} 33$ ) and 17 for $m s p 2$ (8 FC27 and 9 3D7) was found in the P. falciparum population in the Myanmar-China border regions. Two PCR products of $m s p 1$ are similar to that in Thailand and western Cambodia [17, 21]. Allele typing for $m s p 1$ showed that MAD20 (115/215, 53.49\%) was the predominant allelic type in studied areas, which is consistent with the situations in Thailand, Myanmar, Vietnam, Colombia, Equatorial Guinea, and Yunnan Province, China [15, 22-27]. On the contrary, the $\mathrm{K} 1$ family is the most frequent genotype in Laos, Peru, India, Pakistan, Tanzania, Malaysia, and Senegal [28-35]. Allele typing for $m s p 2$ also showed the highest prevalence of FC27 (174/215, 80.93\%) and 3D7 $(163 / 215,75.81 \%)$, which is consistent with these situations in Benin [36]. However, 3D7 is the most frequent in Thailand, Myanmar, Colombia, Malaysia, Senegal, India, Equatorial Guinea and Pakistan [16, 21-23, 26, 30, $32,34,35,37,38$ ]. The overall multiplicity of infection (MOI) of $m s p 1$ and $m s p 2$ was 1.76 and 2.21 , respectively. They were similar to those of Thailand and Laos $[17,28]$, higher than Malaysia, India and Senegal [31, 35, 38], but lower than Ethiopia [39]. The difference may result from the different geographical areas, intensity of malaria transmission and studied populations.

The present study identified 38 alleles of $m s p 1$, including 14 for the K1 family, 23 for the MAD20 family, and 1 for the RO33 family. This genetic diversity of $m s p 1$ in P. falciparum isolates resulted from the different numbers of tripeptide repeat that includes the SAQ, SGP and SGT for K1 and SGG, SVA and SVT for MAD20, which is consistent with the previous studies $[15,22,28,30$, 40]. Similarly, $m s p 2$ also showed a high genetic diversity, with 37 alleles for the 3D7 family and 15 alleles for the FC27 family. This study showed a highly complicated amino acid repeat motifs in the central variable region of 3D7 alleles that contained the different combinations of S, A and G. There were 4 different continual amino acids repeats, including GASGSA (repeat numbers 2 to 4) [41], GGSGSA (repeat numbers 3 to 9) [41-43], GAVASAGS (repeat numbers 2 to 3) [44] and GAGAVAGS (repeat numbers 3 ), as well as 2 single amino acid 
that including GGSA and GAGASAGN, which have also been reported in other studies [14, 41-45]. Several new continual amino acids repeats and single amino acid were also found in this study, including the continual amino acids repeat GAGASGSA (repeat numbers 2), GAGAGA VAGS (repeat numbers 2 to 3), GASGSASGSA (repeat numbers 4 to 5 ), GAVASAGSRD (repeat numbers 5 to 7 ), GAGAGAGAVAGS (repeat numbers 2 to 3), PAT (repeat numbers 2 to 6 ) at the central variable region followed by poly-threonine stretch (repeat numbers 4 to 13) and the intermittent amino acids repeat GAGAGASGSA, GAGASGSAGSGD, GAGAGAGASGSA, as well as the above-mentioned single amino acid except for GGSA at the $3^{\prime}$-end. As reported in previous studies on parasites from Papua New Guinea, Cameroon, Myanmar and China [14, 22, 41, 44], the sequences of the FC27 family of $P$. falciparum isolates in the China-Myanmar border region are conserved at the $3^{\prime}$ and $5^{\prime}$-end, but varied in the number of repeats on SNSPSPPITTTE or SNSRSPPITTTE in the central region.

\section{Conclusion}

The findings of this study have demonstrated that $P$. falciparum clinical isolates in the China-Myanmar border region had a high genetic polymorphism in the $m s p 1$ and $m s p 2$ genes as well as a high multiplicity of infection, suggesting the highly complex population structure of the parasite.

\section{Supplementary information}

Supplementary information accompanies this paper at https://doi. org/10.1186/s12936-019-3003-8.

Additional file 1: Table S1. Multiplicity of infection (MOI) in different groups of age and parasite density.

Additional file 2: Figure S1. Alignment of the predicted amino acid sequences of $\mathrm{K} 1$ allelic types in msp 1 of all isolates from China-Myanmar border region. The shaded areas indicate the central variable region that compared with the isolate PNG830-048 (GenBank accession number AB502646). Identical residues are indicated by dots. Dashes represent spaces inserted to maximize alignment. Each repeat unit is underlined. The total number of each allele is shown in the last sequences.

Additional file 3: Figure S2. Alignment of the predicted amino acid sequences of MAD20 allelic types in msp1 of all isolates from China-Myanmar border region. The shaded areas indicate the central variable region that compared with the isolate Cam46I-1 (GenBank accession number HM153243). Identical residues are indicated by dots. Dashes represent spaces inserted to maximize alignment. Each repeat unit is underlined. The total number of each allele is shown in the last sequences.

Additional file 4: Figure S3. Alignment of the predicted amino acid sequences of 3D7 allelic types in msp2 of all isolates from China-Myanmar border region. The shaded areas indicate the central variable region that compared with the isolate Tak9 (GenBank accession number X53832). Identical residues are indicated by dots. Dashes represent spaces inserted to maximize alignment. Each repeat unit is underlined. The total number of each allele is shown in the last sequences. The 3D7 family consisted of 12 different amino acids repeats, including GASGSA, GGSGSA, GAVASAGS,
GAGAGASGSA, GAGAVAGS, GAGASGSA, GAGAGAVAGS, GASGSASGSA, GAVASAGSRD, GAGASGSAGSGD, GAGAGAGASGSA, and GAGAGAGAVAGS, and the 17 single amino acids comprising of GGSA, GAVAGS, GAGGSGSA, GAGASAGN, GAVASARN, GASGSAGA/S, GASGSAGSGS, GAGAVASAGN, GAG AGASGNA, GAGAGAVASAGN, GAGAGASGSAGSGD, GAGAGASGSAGSRD, GAGAGAGAGAVAGS, GSGAGNGAGNGAGN, GAGAGAGAGAGAVAGS, GAG AGAGASGSAGSGD, and GGSGSAGSGDGNGANP.

Additional file 5: Figure S4. Alignment of the predicted amino acid sequences of FC27 allelic types in msp2 of all isolates in the China-Myanmar border region. The shaded areas indicate the central variable region (GenBank accession number JX885918). Identical residues are indicated by dots. Dashes represent spaces inserted to maximize alignment. Each repeat unit is underlined. The total number of each allele is shown in the last of sequences.

\section{Abbreviations}

MSP1: merozoite surface protein 1; MSP2: merozoite surface protein 2; GMS: Greater Mekong Subregion; MOI: multiplicity of infection.

\section{Acknowledgements}

We are grateful to patients who participated in the study, and to guardians of participating children. We thank Dr. Shuai Ding for providing suggestions for the experiments.

\section{Authors' contributions}

$\mathrm{CZ}$ and $\mathrm{YY}$ designed the experiments and wrote the paper. $\mathrm{CZ}, \mathrm{HZ}$ and $\mathrm{YY}$ participated in the field isolates sampling for this study. CZ performed the experiments. CZ, HZ, QL and YY analysed the data. All authors read and approved the final manuscript.

\section{Funding}

This work was funded by the National Research and Development Plan of China (No. 2016YFC1200500). The funders had no role in the study design, analysis and interpretation of data, or in the writing of the report or decision to submit the article for publication.

\section{Availability of data and materials}

The data generated during this study are included in this published article and Additional files.

\section{Ethical approval and consent to participate}

Plasmodium falciparum isolates of this study were collected during 2006 to 2011 from malaria patients attending local hospitals and clinics along the China-Myanmar border: Laza, Nawei, Mangdong and Nankajiang in Myanmar, and Tengchong, Yingjiang and Mengla in Yunnan, China. The written informed consent was obtained from each patient or the guardian. It is committed not to provide information about the patient to any person unrelated to the study. This protocol approved by the medical ethics committee of Yunnan Institute of Parasitic Diseases.

\section{Consent for publication}

Not applicable.

\section{Competing interests}

The authors declare that they have no competing interests.

\section{Author details}

1 Yunnan Provincial Key Laboratory of Vector-borne Diseases Control and Research, Yunnan Provincial Center of Malaria Research, Yunnan Institute of Parasitic Diseases, Pu'er 665000, Yunnan, China. ${ }^{2}$ School of Life Sciences and Engineering, Foshan University, Foshan 528225, Guangdong, China. ${ }^{3}$ Key Laboratory of Organ Regeneration \& Transplantation of the Ministry of Education, The First Hospital of Jilin University, Changchun 130021, China.

Received: 17 July 2019 Accepted: 11 November 2019

Published online: 19 November 2019 


\section{References}

1. WHO. World malaria report 2018. Geneva: World Health Organization; 2018.

2. Xia ZG, Feng J, Zhou SS. Analysis of malaria epidemic situation in China in 2012. Chin J Parasitol Parasit Dis. 2013;2013:413-8 (in Chinese).

3. Hui F-M, Xu B, Chen Z-W, Cheng X, Liang L, Huang H-B, et al. Spatio-temporal distribution of malaria in Yunnan Province, China. Am J Trop Med Hyg. 2009;81:503-9.

4. Branch O, Casapia WM, Gamboa DV, Hernandez JN, Alava FF, Roncal N, et al. Clustered local transmission and asymptomatic Plasmodium falciparum and Plasmodium vivax malaria infections in a recently emerged, hypoendemic Peruvian Amazon community. Malar J. 2005;4:27.

5. Mazumdar S, Mukherjee P, Yazdani SS, Jain SK, Mohmmed A, Chauhan VS. Plasmodium falciparum merozoite surface protein 1 (MSP-1)-MSP-3 chimeric protein: immunogenicity determined with human-compatible adjuvants and induction of protective immune response. Infect Immun. 2010;78:872-83.

6. Kauth CW, Woehlbier U, Kern M, Mekonnen Z, Lutz R, Mucke N, et al. Interactions between merozoite surface proteins 1, 6, and 7 of the malaria parasite Plasmodium falciparum. J Biol Chem. 2006:281:31517-27.

7. Mahanty S, Saul A, Miller LH. Progress in the development of recombinant and synthetic blood-stage malaria vaccines. J Exp Biol. 2003;206:3781-8.

8. Holder AA, Blackman MJ. What is the function of MSP-1 on the malaria merozoite? Parasitol Today. 1994;10:182-4.

9. Holder AA, Guevara Patino JA, Uthaipibull C, Syed SE, Ling IT, Scott-Finnigan T, et al. Merozoite surface protein 1, immune evasion, and vaccines against asexual blood stage malaria. Parassitologia. 1999:41:409-14.

10. Genton B, Al-Yaman F, Betuela I, Anders RF, Saul A, Baea K, et al. Safety and immunogenicity of a three-component blood-stage malaria vaccine (MSP1, MSP2, RESA) against Plasmodium falciparum in Papua New Guinean children. Vaccine. 2003;22:30-41.

11. Anders RF, McColl DJ, Coppel RL. Molecular variation in Plasmodium falciparum: polymorphic antigens of asexual erythrocytic stages. Acta Trop. 1993;53:239-53

12. Fenton B, Clark JT, Khan CM, Robinson JV, Walliker D, Ridley R, et al. Structural and antigenic polymorphism of the 35- to 48-kilodalton merozoite surface antigen (MSA-2) of the malaria parasite Plasmodium falciparum. Mol Cell Biol. 1991:11:963-71.

13. Snewin VA, Herrera M, Sanchez G, Scherf A, Langsley G, Herrera S. Polymorphism of the alleles of the merozoite surface antigens MSA1 and MSA2 in Plasmodium falciparum wild isolates from Colombia. Mol Biochem Parasitol. 1991:49:265-75.

14. Smythe JA, Coppel RL, Day KP, Martin RK, Oduola AM, Kemp DJ, et al. Structural diversity in the Plasmodium falciparum merozoite surface antigen 2. Proc Natl Acad Sci USA. 1991;88:1751-5.

15. Yuan L, Zhao H, Wu L, Li X, Parker D, Xu S, et al. Plasmodium falciparum populations from northeastern Myanmar display high levels of genetic diversity at multiple antigenic loci. Acta Trop. 2013;125:53-9.

16. Perandin F, Manca N, Calderaro A, Piccolo G, Galati L, Ricci L, et al. Development of a real-time PCR assay for detection of Plasmodium falciparum, Plasmodium vivax, and Plasmodium ovale for routine clinical diagnosis. J Clin Microbiol. 2004;42:1214-9.

17. Snounou G, Zhu X, Siripoon N, Jarra W, Thaithong S, Brown KN, et al. Biased distribution of msp1 and msp2 allelic variants in Plasmodium falciparum populations in Thailand. Trans R Soc Trop Med Hyg. 1999;93:369-74

18. Paganotti GM, Babiker HA, Modiano D, Sirima BS, Verra F, Konate A, et al. Genetic complexity of Plasmodium falciparum in two ethnic groups of Burkina Faso with marked differences in susceptibility to malaria. Am Trop Med Hyg. 2004;71:173-8.

19. Healer J, Murphy V, Hodder AN, Masciantonio R, Gemmill AW, Anders RF, et al. Allelic polymorphisms in apical membrane antigen-1 are responsible for evasion of antibody-mediated inhibition in Plasmodium falciparum. Mol Microbiol. 2004:52:159-68.

20. Day KP, Marsh K. Naturally acquired immunity to Plasmodium falciparum Immunol Today. 1991:12:68-71.

21. Gosi P, Lanteri CA, Tyner SD, Se Y, Lon C, Spring M, et al. Evaluation of parasite subpopulations and genetic diversity of the msp1, msp2 and glurp genes during and following artesunate monotherapy treatment of Plasmodium falciparum malaria in Western Cambodia. Malar J. 2013;12:403.
22. Kang JM, Moon SU, Kim JY, Cho SH, Lin K, Sohn WM, et al. Genetic polymorphism of merozoite surface protein-1 and merozoite surface protein-2 in Plasmodium falciparum field isolates from Myanmar. Malar J. 2010;9:131

23. Soe TN, Wu Y, Tun MW, Xu X, Hu Y, Ruan Y, et al. Genetic diversity of Plasmodium falciparum populations in southeast and western Myanmar. Parasit Vectors. 2017:10:322

24. Kaneko O, Kimura M, Kawamoto F, Ferreira MU, Tanabe K. Plasmodium falciparum: allelic variation in the merozoite surface protein 1 gene in wild isolates from southern Vietnam. Exp Parasitol. 1997;86:45-57.

25. Gomez D, Chaparro J, Rubiano C, Rojas MO, Wasserman M. Genetic diversity of Plasmodium falciparum field samples from an isolated Colombian village. Am J Trop Med Hyg. 2002;67:611-6.

26. Chen JT, Li J, Zha GC, Huang G, Huang ZX, Xie DD, et al. Genetic diversity and allele frequencies of Plasmodium falciparum msp1 and msp2 in parasite isolates from Bioko Island, Equatorial Guinea. Malar J. 2018;17:458.

27. Zhu X, Zhou L, Liu Q, Gao X. Genotype and sequence analysis of merozoite surface protein 1 of Plasmodium falciparum isolates in Yunnan province. Chin J Parasitol Parasit Dis. 1999;17:155-8 (in Chinese).

28. Khaminsou N, Kritpetcharat O, Daduang J, Charerntanyarak L, Kritpetcharat $P$. Genetic analysis of the merozoite surface protein- 1 block 2 allelic types in Plasmodium falciparum clinical isolates from Lao PDR. Malar J. 2011;10:371.

29. Chenet SM, Branch OH, Escalante AA, Lucas CM, Bacon DJ. Genetic diversity of vaccine candidate antigens in Plasmodium falciparum isolates from the Amazon basin of Peru. Malar J. 2008;7:93.

30. Joshi H, Valecha N, Verma A, Kaul A, Mallick PK, Shalini S, et al. Genetic structure of Plasmodium falciparum field isolates in eastern and northeastern India. Malar J. 2007:6:60

31. Bharti PK, Shukla MM, Sharma YD, Singh N. Genetic diversity in the block 2 region of the merozoite surface protein-1 of Plasmodium falciparum in central India. Malar J. 2012;11:78.

32. Ghanchi NK, Martensson A, Ursing J, Jafri S, Bereczky S, Hussain R, et al. Genetic diversity among Plasmodium falciparum field isolates in Pakistan measured with PCR genotyping of the merozoite surface protein 1 and 2 . Malar J. 2010;9:1.

33. Carlsson AM, Ngasala BE, Dahlstrom S, Membi C, Veiga IM, Rombo L, et al. Plasmodium falciparum population dynamics during the early phase of anti-malarial drug treatment in Tanzanian children with acute uncomplicated malaria. Malar J. 2011;10:380.

34. Mohd Abd Razak MR, Sastu UR, Norahmad NA, Abdul-Karim A, Muhammad A, Muniandy PK, et al. Genetic diversity of Plasmodium falciparum populations in malaria declining areas of Sabah, East Malaysia. PLoS ONE. 2016;11:e0152415.

35. Niang M, Loucoubar C, Sow A, Diagne MM, Faye O, Faye O, et al. Genetic diversity of Plasmodium falciparum isolates from concurrent malaria and arbovirus co-infections in Kedougou, southeastern Senegal. Malar J. 2016;15:155.

36. Ogouyemi-Hounto A, Gazard DK, Ndam N, Topanou E, Garba O, Elegbe P, et al. Genetic polymorphism of merozoite surface protein-1 and merozoite surface protein-2 in Plasmodium falciparum isolates from children in South of Benin. Parasite. 2013;20:37.

37. Kuesap J, Chaijaroenkul W, Ketprathum K, Tattiyapong P, Na-Bangchang K Evolution of genetic polymorphisms of Plasmodium falciparum merozoite surface protein (PfMSP) in Thailand. Korean J Parasitol. 2014;52:105-9.

38. Atroosh WM, Al-Mekhlafi HM, Mahdy MA, Saif-Ali R, Al-Mekhlafi AM, Surin J. Genetic diversity of Plasmodium falciparum isolates from Pahang, Malaysia based on MSP-1 and MSP-2 genes. Parasit Vectors. 2011;4:233.

39. Mohammed H, Kassa M, Mekete K, Assefa A, Taye G, Commons RJ. Genetic diversity of the msp-1, msp-2, and glurp genes of Plasmodium falciparum isolates in Northwest Ethiopia. Malar J. 2018;17:386.

40. Scopel KK, Fontes CJ, Ferreira MU, Braga EM. Plasmodium falciparum: IgG subclass antibody response to merozoite surface protein-1 among Amazonian gold miners, in relation to infection status and disease expression. Exp Parasitol. 2005;109:124-34.

41. Basco LK, Tahar R, Escalante A. Molecular epidemiology of malaria in Cameroon. XVIII. Polymorphisms of the Plasmodium falciparum merozoite surface antigen-2 gene in isolates from symptomatic patients. Am J Trop Med Hyg. 2004;70:238-44 
42. Thomas AW, Carr DA, Carter JM, Lyon JA. Sequence comparison of allelic forms of the Plasmodium falciparum merozoite surface antigen MSA2. Mol Biochem Parasitol. 1990;43:211-20.

43. Felger I, Marshal VM, Reeder JC, Hunt JA, Mgone CS, Beck HP. Sequence diversity and molecular evolution of the merozoite surface antigen 2 of Plasmodium falciparum. J Mol Evol. 1997;45:154-60.

44. Jiang GF, Chen PQ, Wang SQ. Genotyping and sequence analysis of the merozoite surface antigen 2 of Plasmodium falciparum in Hainan Province, China. Chin J Parasit Dis Con. 2002:15:7-10 (in Chinese).
45. Eisen D, Billman-Jacobe H, Marshall VF, Fryauff D, Coppel RL. Temporal variation of the merozoite surface protein-2 gene of Plasmodium falciparum. Infect Immun. 1998:66:239-46.

\section{Publisher's Note}

Springer Nature remains neutral with regard to jurisdictional claims in published maps and institutional affiliations.
Ready to submit your research? Choose BMC and benefit from:

- fast, convenient online submission

- thorough peer review by experienced researchers in your field

- rapid publication on acceptance

- support for research data, including large and complex data types

- gold Open Access which fosters wider collaboration and increased citations

- maximum visibility for your research: over $100 \mathrm{M}$ website views per year

At BMC, research is always in progress.

Learn more biomedcentral.com/submissions 